BMJ Open

Sport \&

Exercise

Medicine

\section{The waterpolo shoulder paradigm: results of ultrasound surveillance at poolside}

To cite: Galluccio F, Bellucci E, Porta F, et al. The waterpolo shoulder paradigm: results of ultrasound surveillance at poolside. BMJ Open Sport Exerc Med 2017;3: 0000211. doi:10.1136/bmjsem-2016000211

Accepted 18 January 2017

\section{CrossMark}

\footnotetext{
${ }^{1}$ Division of Rheumatology, Department of Clinical and Experimental Medicine, University of Florence, Florence, Italy ${ }^{2}$ Department of Neurosciences, Psychology, Drug Research and Child Health, University of Florence, Florence, Italy ${ }^{3}$ Section of Autoimmune Diseases, Department of Translational Medical Sciences, University of Naples Federico II, Naples, Italy

${ }^{4}$ Anti-doping and Health Care Committee of the Italian Football Federation, Rome, Italy
}

Correspondence to Dr Felice Galluccio, Department of Clinical and Experimental Medicine, University of Florence, 50139 Firenze Fl, Italy; felicegalluccio@gmail.com

\section{ABSTRACT}

Background Waterpolo consists of a combination of swimming and throwing with close contact between players. The shoulder is the most frequently injured joint, with a combination of rotator cuff tear and tendinopathy, long head biceps tendinopathy, superior labral lesions and shoulder impingement. This unique combination is a challenge for the clinician who must determine which of these shoulder pathologies is responsible for the onset of pain and the best strategy to rehabilitate the joint and prevent recurrence.

Aim The aim of this study was to estimate with ultrasound the frequency and characteristics of shoulder injuries in waterpolo players competing in different leagues.

Methods Forty-two players from two clubs in the premier and second Italian league were enrolled in the study. Standard and dynamic shoulder ultrasound scans were performed on all athletes.

Results Ultrasound investigation showed that almost all players had injuries of the shoulders; only four players did not show any shoulder modification. Thirteen athletes who had shoulder pain during the ultrasound examination showed subacromion deltoid bursitis and/or long head biceps tendinitis. No statistically significant differences in the frequency and characteristics of shoulder modifications or injuries were detected between players of the premier or second league.

Conclusion Shoulder injuries are very common in waterpolo players and comprise a peculiar and complex combination of rotator cuff tendinopathy and tears, long head biceps tendinopathy, impingement, subacromion deltoid bursitis and superior labral lesions. The use of ultrasound has been shown to be of considerable help in highlighting the modifications of the shoulder structures at an early asymptomatic stage. The ability to perform real-time scanning at the poolside makes ultrasound a useful tool in the rapid management and regular follow-up of shoulder modifications in everyday practice in sport medicine.

\section{BACKGROUND}

Waterpolo is one of the oldest Olympic team competitions and originated in England as an aquatic version of rugby. The game consists of a combination of

\section{What are the new findings?}

- There is no difference in the kind or incidence of shoulder lesions between players of the premier and second or minor leagues.

- Despite the fact that the dominant limb shoulder is most affected, bilateral lesions are common, affecting the same structures.

How might it impact on clinical practice in the future?

Identifying subclinical shoulder ultrasound alterations at an early asymptomatic stage.

- Real-time scanning at poolside makes ultrasound a remarkably useful tool in the rapid management of shoulder alterations and injuries, both during training and the sport season.

swimming and throwing with close contact between players. Moreover, the gameplay is physically demanding with rapid changes between high and low intensity intervals. ${ }^{1}$ The most commonly injured area is the shoulder, ${ }^{2}{ }^{3}$ due to repetitive microtraumas and contact traumas in swimming and throwing or tackling and blocking. This is combined with biomechanical factors such as head-up swimming, overhead arm action and the peculiar movement of shooting. In addition, some athletes begin their careers as swimmers with a high mileage in the pool, resulting in gleno-humeral multidirectional hypermobility (swimmer shoulder). ${ }^{45}$ The most common shoulder injuries are rotator cuff tear and tendinopathy, long head biceps tendinopathy, superior labral lesions (SLAP) and shoulder impingement. ${ }^{6}$ 7 This unique combination is a challenge for the clinician who has to determine which of these shoulder pathologies is responsible for the onset of pain and the 
best strategy to rehabilitate the joint and prevent recurrence. Only a few descriptive papers have been published and the majority consider waterpolo as a sport with a high risk for injuries only in elite players (major leagues or national selection), ${ }^{8} 9$ while second or minor league or junior players are not considered.

Ultrasonography (US) is a fast, cheap, accurate and dynamic technique for the assessment and diagnosis of shoulder impingement, instability and rotator cuff disorders. ${ }^{10}$

The aim of this study was to use US to estimate the frequency and characteristics of shoulder injuries in waterpolo players competing in different leagues.

\section{METHODS}

Forty-two players from two clubs of the premier and second Italian league were enrolled in the study. The study was approved by the local ethics committee and all participants signed an informed consent form. The only exclusion criterion was the inability to sign the consent form.

US evaluations were carried out using ESAOTE Mylab 25 Gold with a 5-12 $\mathrm{MHz}$ linear array probe (LA523). Standard US scans were performed as described by the guidelines of the European Society of Musculoskeletal Radiology. ${ }^{11}$ US evaluation includes the following anatomical structures: gleno-humeral joint, rotator cuff (supraspinatus, infraspinatus, teres minor and subscapularis tendons), long head biceps tendon and subacromion deltoid bursa. Dynamic US was performed in all athletes for the evaluation of impingement.

Data are presented as number and percentage; the $\chi^{2}$ test was run on SAS 9.3 software to compare groups.

\section{RESULTS}

The US investigation found that almost all players had modifications or injuries of the shoulder structures (table 1).

Only four players had no shoulder modifications. The most common bilateral injury was tendinopathy of the supraspinatus $(38.10 \%)$, frequently associated with partial thickness tear $(30.95 \%)$, followed by subscapularis tendinopathy $(21.43 \%)$, a variable grade of subacromion deltoid bursitis (16.67\%), shoulder impingement (14.29\%), subscapularis partial thickness tear $(9.52 \%)$ and long head biceps tendinopathy $(9.52 \%)$. In the dominant arm, impingement and supraspinatus tear were the most frequent injuries $(21.43 \%)$. Because postero-superior and antero-superior impingement were equally frequent, the values have been analysed together. SLAP tear was detected in $4.76 \%$ of the players in the shoulder of the dominant arm and in $2.38 \%$ in the shoulder of the nondominant arm. At the time of the US evaluation, only 13 athletes complained of shoulder pain (30.95\%). In these athletes the main modifications detected were subacromion deltoid bursitis (63\%) and long head biceps tendinitis $(48 \%)$, both of which were characterised by a high grade of inflammation with hypervascularity by power Doppler US imaging.

No statistically significant differences in the frequency and characteristics of shoulder modifications were detected between players of the premier or second league teams (table 2).

\section{DISCUSSION}

Shoulder injuries are very common in waterpolo players and comprise a peculiar and complex combination of rotator cuff tendinopathy and tears, long head biceps tendinopathy, shoulder impingement, subacromion deltoid bursitis and SLAP tear.

Table 1 Descriptive analysis of the shoulder modifications observed in waterpolo players

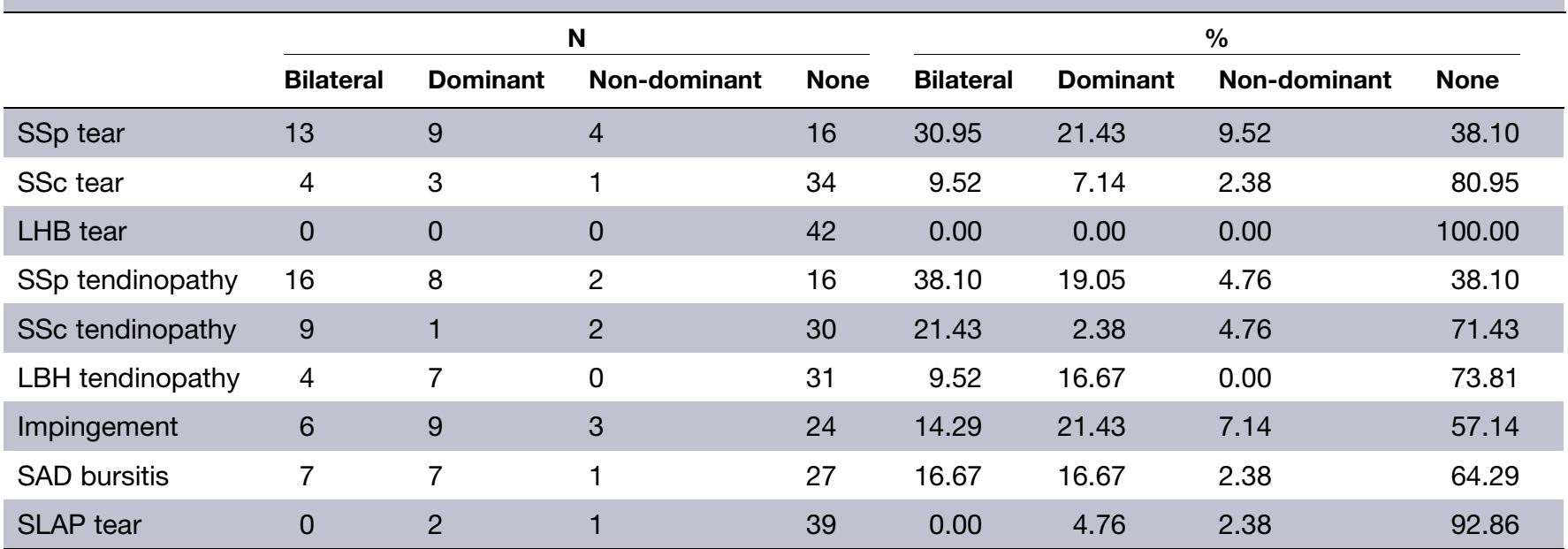

SSp, supraspinatus; SSc, subscapularis; LHB, long head biceps; SAD, subacromion deltoid; SLAP, superior labral lesion. 
Table 2 Comparison of data obtained from teams playing in elite and minor (second/junior) leagues

\begin{tabular}{|c|c|c|c|c|c|c|}
\hline & \multicolumn{2}{|c|}{ Team (n) } & \multirow[b]{2}{*}{ p Value } & \multicolumn{2}{|c|}{ Team (\%) } & \multirow[b]{2}{*}{ p Value } \\
\hline & Elite & Minor & & Elite & Minor & \\
\hline SSp tear & 13 & 13 & 1 & 50 & 50 & 1 \\
\hline LHB tear & 0 & 0 & NA & 0 & 0 & NA \\
\hline SSp tendinopathy & 13 & 14 & 0.74 & 48.15 & 51.85 & 0.74 \\
\hline LBH tendinopathy & 5 & 6 & 0.72 & 45.45 & 54.55 & 0.72 \\
\hline Impingement & 11 & 7 & 0.21 & 61.11 & 38.89 & 0.21 \\
\hline SAD bursitis & 7 & 8 & 0.74 & 46.67 & 53.33 & 0.74 \\
\hline SLAP tear & 2 & 1 & 1 & 66.67 & 33.33 & 1 \\
\hline
\end{tabular}

SSp, supraspinatus; SSc, subscapularis; LHB, long head biceps; SAD, subacromion deltoid; SLAP, superior labral lesion.

In the present cohort of athletes, our data clearly show that there is a difference in the incidence of bilateral injuries and between the shoulders of dominant or non-dominant arms. In fact, the dominant arm is always more affected than the non-dominant arm, but it is interesting to note that the structures involved are the same in both arms. These results highlight the fact that there may be several causes leading to shoulder modifications and injuries. In fact, they may derive specifically from the intensity/frequency of some pivotal movements performed either during training or during matches. In waterpolo players, these data focus attention on the fact that adequate and specific athletic preparation may be needed to reduce the risk and the number and repetition of shoulder lesions. For this reason, it may be suggested that, at the beginning and during the sport season, both the muscular and peri/articular structures should be carefully evaluated in all athletes. In particular, this might be achieved by a careful evaluation of the anatomical structure of each athlete with identification of the most developed and undeveloped muscles to prompt a training plan which may thus reduce shoulder injuries. It is well known that these injuries can lead to chronic shoulder pain and disability. This approach may lead to prompt identification of shoulder structures likely to be affected and help in building a correct training programme. This may prevent further damage to the shoulder structures and avoid the persistence of those factors that could cause shoulder modifications and injuries.

However, our data are not in agreement with previous reports. ${ }^{812}$ Our data clearly show that there is no difference in the kind or incidence of shoulder lesions between players of the premier and second league. In our cohort, the use of US proved to be of considerable help, highlighting in the majority of athletes the modifications of the shoulder structures at an early asymptomatic stage. Furthermore, the ability to perform real-time scanning at the poolside makes US a remarkably useful tool in the rapid management of shoulder modification of these players. Moreover, the possibility of a regular follow-up of the shoulder in athletes in whom a modification or injury has been identified makes US a 'friendly', low cost and very helpful tool to be used in everyday practice in sport medicine.

\section{CONCLUSION}

Our data, which need confirmation in future studies on a larger cohort, show that it is possible to identify precisely subclinical shoulder US alterations in both symptomatic and asymptomatic cases as early as possible at the poolside, both during training and in the sport season.

In waterpolo players, the future perspective is therefore to use US to detail the condition of the shoulder and consequently establish a prevention programme tailored to the shoulder characteristics of each athlete. This specific programme may reinforce those shoulder muscles that will help to avoid evolution to impingement and SLAP and supraspinatus tears. Eventually, tailoring of this programme could help to reduce the risk of shoulder dysfunction, disability and damage that usually limits and impairs the activity of waterpolo players.

Contributors FG: Design of the study, acquisition, interpretation and drafting of the work. EB, FP, TB: Acquisition and data collection. LT: Data analysis and statistics. ADP, DB: Critical revision. MM-C: Conception of the work and final approval.

Competing interests None declared.

Ethics approval Local ethics commitee AOU Careggi.

Provenance and peer review Not commissioned; externally peer reviewed. 
Open Access This is an Open Access article distributed in accordance with the Creative Commons Attribution Non Commercial (CC BY-NC 4.0) license, which permits others to distribute, remix, adapt, build upon this work noncommercially, and license their derivative works on different terms, provided the original work is properly cited and the use is non-commercial. See: http:// creativecommons.org/licenses/by-nc/4.0/

(C) Article author(s) (or their employer(s) unless otherwise stated in the text of the article) 2017. All rights reserved. No commercial use is permitted unless otherwise expressly granted.

\section{REFERENCES}

1 Lozovina V, Pavicic L. Anthropometric changes in elite male water polo players: survey in 1980 and 1995. Croat Med J 2004;45:202-5.

2 Colville JM, Markman BS. Competitive water polo. Upper extremity injuries. Clin Sports Med 1999;18:305-12.

3 Webster MJ, Morris ME, Galna B. Shoulder pain in water polo: a systematic review of the literature. J Sci Med Sport 2009;12:3-11.

4 Bak K. The practical management of swimmer's painful shoulder: etiology, diagnosis, and treatment. Clin J Sport Med 2010;20:386-90.

5 Richardson AB, Jobe FW, Collins HR. The shoulder in competitive swimming. Am J Sports Med 1980;8:159-63.
6 Klein M, Tarantino I, Warschkow R, et al. Specific shoulder pathoanatomy in semiprofessional water polo players: a magnetic resonance imaging study. Orthop J Sports Med 2014;2:2325967114531213.

7 Jerosch J, Castro WH, Drescher H, et al. [Magnetic resonance morphologic changes in shoulder joints of world class water polo players]. Sportverletz Sportschaden 1993;7:109-14.

8 Mountjoy M, Junge A, Benjamen S, et al. Competing with injuries: injuries prior to and during the 15th FINA World Championships 2013 (aquatics). Br J Sports Med 2015;49:37-43.

9 Mountjoy M, Junge A, Alonso JM, et al. Sports injuries and illnesses in the 2009 FINA World Championships (aquatics). Br J Sports Med 2010;44:522-7.

10 lannotti JP, Ciccone J, Buss DD, et al. Accuracy of office-based ultrasonography of the shoulder for the diagnosis of rotator cuff tears. J Bone Joint Surg Am 2005;87:1305-11.

11 European Society of Musculoskeletal Radiology. www.essr.org/html/ img/pool/shoulder.pdf

12 Tate A, Turner GN, Knab SE, et al. Risk factors associated with shoulder pain and disability across the lifespan of competitive swimmers. J Athl Train 2012;47:149-58. 